\title{
IDÉIAS
}

\section{Parlamentarismo será solução para impasses}

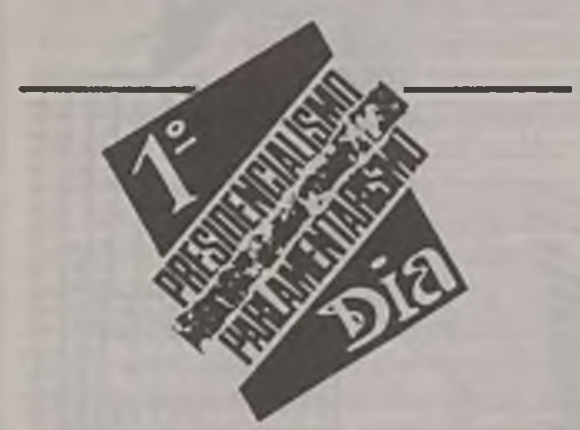

"Nós estamos, neste instante, na fase decisiva para a definição do sistema de Governo que irá presidir a vida brasileira.

Não se trata de uma questão meramente formal ou de gosto pelas formulações juridicas. Trata-se, na verdade, de encontrarmos um instrumento, um mecanismo por meio do qual se possa superar as crises que continuamente vitimaram a vida brasileira republicana.

Com elevado interesse ouvi as manifestações dos ilustres Professores da França e da Espanha. Ora, nós não podemos trasladar modelos de outros paises sem antes fazermos uma análise da realidade nacional, da realidade politica e histórica do Brasil. Podemos dizer, senhores Professores, caros Constituintes, que a história politica brasileira, republicana, caracteriza-se pelo imenso divórcio que sempre se estabeleceu entre o Poder Executivo e o Poder legislativo. Um Presidente da República colocado como um ser isolado, que ao mesmo tempo cra frágil e lodo poderoso. Poderoso, na medida em que demitia, nomeava $\mathrm{c}$ adınitia. Mas, ao mesmo tempo frágil, no seu distanciamento com o Congresso Nacional e o Parlamento, impossibilitado, muitas vezes, da consecução de planos de Governo, inviabilizando-se nesta resistência que se tornou uma constante. A realização de mudanças, e a proposta de mudanças encontravam obstáculos intransponiveis na falta de diálogo e de convivência entre o Executivo e o Legislativo. E o militarismo prevaleceu na vida republicana brasi-

Professor de Direito Constitucional da Universidade Federal de São Paulo, e Expositor do 1: dia do Seminário Internacional.
Prof. Miguel Reale Júnior

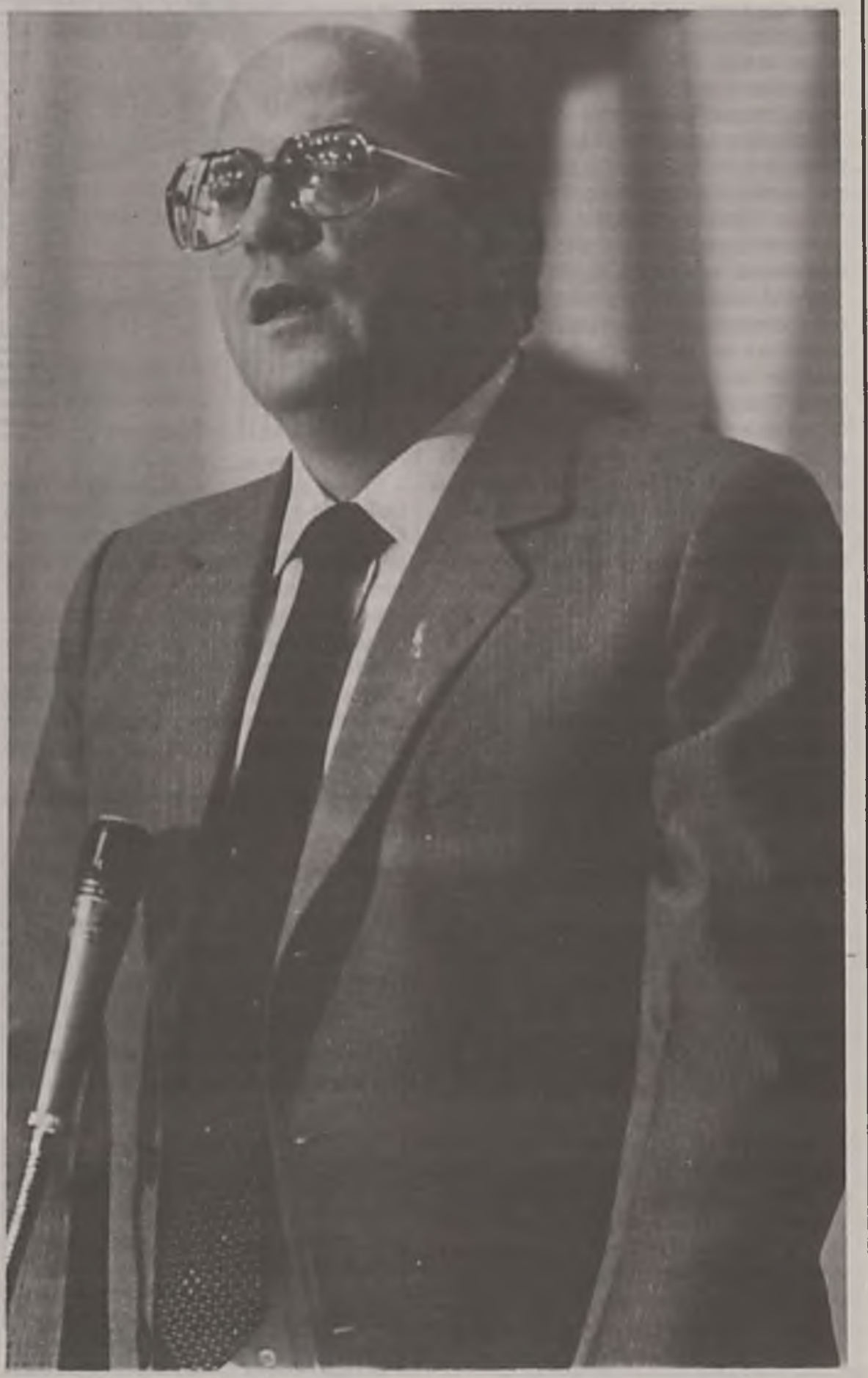




\section{IDÉIAS}

leira. Não seria ocioso lembrar uma frase que Campos Salles disse a Prudente de Moraes. Prudente de Moraes, Presidente da Assembléia Nacional Constituinte, colocava-se como candidato contra o candidato Marechal Deodoro da Fonseca. E, então, Campos Salles disse a Prudente de Moraes: "não seria mais prudente, mais conveniente, que você retirasse a sua candidatura, senão fecham o Congresso?"' $E$ essa frase, dita no nascer da nossa República, praticamente foi uma constante.

Sempre a indicação da prudência de não se praticar a democracia sob pena do fechamento do Congresso, e o Congresso foi fechado inúmeras vezes, foi desconhecido e desmerecido. O Congresso brasileiro foi desmerecido pela política dos governadores, que estabeleceu o sistema da barganha e das benesses, o fortalecimento dos Governos locais, que davam sustentação ao Governo da República com o demérito do Parlamento. Os Deputados transformados apenas em recebedores de benefícios para dar vantagens, para dar apoio político ao governo central. E há outro dado da sociologia politica brasileira. É o demérito do Legislativo, é a descrença do povo com relação ao Parlamentar e ao congressista, é algo que está impregnado na vida brasileira de forma absolutamente injusta, mas é um dado de realidade do qual não podemos estar afastados. Há, portanto, esses dados que são fundamentais. A figura do Presidente da República, que se consolidou através desses 100 anos de presidencialismo, mas um Presidente da República que é frágil e poderoso ao mesmo tempo. Esse distanciamento, divórcio entre o Executivo e o Legislativo, as crises se resolvendo sempre através do fechamento do Congresso Nacional, a militarização da vida republicana brasileira e o demérito do Poder Legislativo, e o enfraquecimento do Poder Legislativo nos últimos 20 anos transformado em mero órgão homologador das decisões do poder central.

Mas, ao lado disso, há um outro dado que compõe obrigatoriamente a sociologia política brasileira, que foi o movimento em favor das eleições diretas. Este movimento em favor das eleições diretas trou$x e$, sem dúvida nenhuma, a crença enraizada de que se decide a vida do país no momento em que se elege o Presidente da República. Não tem apenas o significado de se fazer uma opção em favor deste ou daquele candidato à Presidência da República. Mas há, sim, uma convicção de que está a decidir a vida brasileira, neste instante, mesmo porque os problemas na- cionais só são discutidos em profundidade no momento da disputa eleitoral para Presidência da República. Essa eleição para a Presidência da República tem um significado efetivo de cidadania, de participação nos destinos da Nação, e não é apenas, portanto, a possibilidade de uma escolha, é a possibilidade de participação ativa, de exercício ativo da cidadania. Este é o significado que está incrustado na alma do povo brasileiro hoje. Não há proposta que não venha estipulando a eleição direta para Presidente da República. Ora, esta eleição direta para Presidente da República dará a este Presidente o caráter de ser o delegado nacional. Ele irá às praças públicas e às televisões. Ele irá convencer o povo, que será convencido. Será ouvido e convencido por este candidato à Presidência da República, que por maio-

Não queremos a construção de um modelo teórico, que não seja aplicável à realidade, um modelo que busque eficácia, porque o modelo que gera impasse, não vai sem dúvida nenhuma, alcançar os objetivos desta Constituinte.

ria absoluta vai chegar ao Palácio do Planalto com 35 a 40 milhões de votos.

Na verdade, o plano de governo já vem definido e desenhado através da eleição à Presidência da República. Ora, este é um dado que não pode ser desconhecido. Se nós estabelecermos um regime Parlamentar, a própria Constituinte poderá sofrer a acusação de estar, de forma oblíqua, retirando aquilo que o povo tanto exigiu indo às praças públicas e às ruas, durante o ano de 1984.

Ora, se estabelecermos um regime Parlamentar atribuindo-se a administração e a responsabilidade da política de governo a um Primeiro-Ministro, haverá, sem dúvida nenhuma, um descontentamento popular, e os candidatos à Presidência da República, seja em 88 ou 89 , irão concorrer à Presidência da República tendo co- mo plano ou tendo como programa essencial recobrar aquilo que o povo sempre desejou dar ao Presidente da República, que era a plena capacidade de condução da vida administrativa brasileira.

Não tenhamos dúvida de que aquilo que ocorreu em 1963, com o Presidente João Goulart, que levou uma maciça negação do Parlamentarismo com $98 \%$ da população brasileira, vai-se repetir, mesmo porque os candidatos à Presidência da República vão ser como bandeiras à mudança da Constituição se ela vier a adotar o regime Parlamentar.

É um dado, portanto, inafastável este. E a eleição direta para Presidente da República que tem um significado de crença, é hoje um tabu que não pode ser desfeito. E a história impõe os seus limites. Esse é um dado que está aí.

Diante disto, diante da impossibilidade de se desfazer a história, diante da impossibilidade de adotarmos um regime Parlamentar que retirasse a crise do $\mathrm{Pa}$ lácio do Planalto e conduzisse as crises para que elas fossem superadas através da articulação politica no Congresso, por falta de partidos políticos estruturados, por falta de uma burocracia estatal preparada, como bem ressaltou o Ministro Aluízio Alves, nós temos que, sem dúvida alguma, procurar uma solução sui generis. Não podemos ficar na forma do presidencialismo puro, esse Presidente da República isolado, esse homem só, sozinho, esse divórcio que se sente presente na vida brasileira republicana. Esse presidencialismo imperial, que acaba por sempre levar ao confronto. Esta consciência que o Presidente da República tem de que ele tem todos os poderes na mão. Mesmo quando há uma Assembléia Nacional Constituinte o Presidente da República sente-se no direito, sente a consciência de que, indo à televisão para dizer de seu mandato, ele está falando na qualidade de Presidente da República exercendo um direito seu, para tomarmos a análise do dia de hoje e mostrar que é necessário mudar o presidencialismo. Mudar o presidencialismo no sentido de que o Presidente da República é a delegado nacional, tem a força de um imenso respaldo popular, mas não é um poder unipessoal.

É necessário encontrarmos formas que viabilizem a articulação política, que agilizem a negociação, que valorizem o Legislativo, estabeleça-se o regime de coresponsabilidade entre o Executivo e o Legislativo. Que se faça um regime.

Ora, nós temos essas duas grandes missões a cumprir, para quebrar com as difi- 
culdades. Reduzir o poder unipessoal do Presidente da República, de um lado, e favorecer e fortalecer o Legislativo e o Congresso Nacional.

$O$ regime parlamentarista seria, sem chivida nenhuma, uma oportunidade para os impasses, para a anarquia parlamentar. O sistema de dinastia, como proposto pela Comissão Afonso Arinos, ou proposto de forma engenhosa, inteligente, pelo ilustre Senador.José Fogaça, na sua proposta, na Subcomissão, leva, a meu ver, possivelmente a impasses que conduzirão a uma paralisia, na medida em que se estabelece, de um lado, o Presidente da República, eleito por voto direto, de outro lado, um chefe de governo responsável pela política de governo e pela administração pública. Mas ao mesmo tempo se estabelece o projeto Fogaça, da mesma forma que o projeto Afonso Arinos, que o plano de governo é de responsabilidade do Primeiro-Ministro. De outro lado, é responsável pelo envio do orçamento o Presidente da República. A iniciativa de lei cabe ao Presidente da República, mas a iniciativa de lei é algo que, na verdade, está obrigatoriamente no pläno de governo. Não se pode pensar numa iniciativa de lei que não esteja vinculada a um plano de governo que não é do Presidente da República. Assim, nós estaremos viabilizando um impasse, nós estaremos permitindo que o Presidente da Repúblicai seja imobilizado pelo Primeiro-Ministro, e o Primeiro-Ministro seja imobiliza. do pelo Presidente da República.

Ora, eu creio que há a possibilidade de uma fórmula intermediária e, dentro de um sistema igualmente considerado, passo a pender para o Presidente da República maiores responsabilidades do que o Primeiro-Ministro. Assim, a nossa proposta é no sentido de um sistema de co-responsabilidade, e que o Primeiro-Ministro seja indicado pelo Presidente da República, consultados os Presidentes dos partidos políticos, porque é necessária a valorizaçào dos partidos políticos que compõem a maioria. Nós sentimos que recentemente essa crise ocorreu quando o Presidente da República consultou os Presidentes dos partidos politicos para a composição do seu ministério. Entendia-se que isso era do poder do Presidente da República.

Tudo isso é normal. Na articulação política e na vida democrática, é necessário, por sua vez, a meu ver, que haja a especulação constitucional daquilo que deve ser fruto da política, mas é necessário, na vida brasileira, que isso esteja estipulado.
O Presidente da República passa uma consulta aos Presidentes dos partidos politicos que compõem a maioria para se revelar que essa prática não é uma prática que diminua o Presidente da República. Ela é uma prática que bota o Presidente da República envolto num processo político maior.

Ora, o Presidente da República, consultando os Presidentes dos partidos políticos que compōem a maioria, indica o nome a ser aprovado por maioria absoluta pelo Congresso Nacional em sessão unicameral. Assim, esse Presidente da República terá o respaldo. Vamos dizer que ele seja um superministro, sim, um superministro, mas que surge com que qualidade? Com a qualidade de ter a aprovação do Congresso Nacional, de um imen-

\section{Nossa proposta é no sentido de um sistema de co-responsabilidade, e que o Primeiro-Ministro seja indicado pelo Presidente da República, consultados os Presidentes dos partidos políticos, porque é necessária a valorização dos partidos que compõem a maioria.}

so respaldo político para duas funçōes essenciais.

Primeiro, ser o coordenador da ação ministerial, participar do Conselho de Ministros, onde se estabelece o plano de governo. O plano de governo não é do Presidente da República, que já discutiu esse plano com a população. Mas ele é detalhado por um Conselho de Ministros do qual participa o Primeiro-Ministro.

Ele participa, portanto, da análise, ele participa da elaboração do plano, das decisōes e, depois, ele vai ser o responsável pela execução das decisões tomadas, porque ele vai ser coordenador da ação governamental.

Há um defeito, sem dúvida nenhuma, que ocorre por falta de capacidade de tempo, de possibilidades do Presidente da
República, que tem sobre seus ombros tantas tarefas. Ele coordena as ações dos ministérios, ele estabelece uma unidade de governo para que os ministérios saibam o que se passa nos outros ministérios, para que o governo seja uma voz única, para que se estabeleçam prioridades, se discutam prioridades com os ministros, e esta é uma grande, imensa tarefa, de alguém que será o representante do Congresso Nacional. A tarefa conjunta de conduzir a administração. Este não é o PrimeiroMinistro fraco. Muitos chegam a fazer a crítica a esta proposta, de que seria um Primeiro-Ministro fraco. Eu acho que eu criei um ministro que tem uma imensa força, na medida em que ele vai coordenar a ação ministerial, vai coordenar a ação de governo que indica a execução do plano e, mais, ele tem a função de coordenador, de mediador, mediador entre o Executivo e o Legislativo, entre o Presidente da República e o Congresso. Ele faz esse papel de mediação, de fazer com que chegue ao Presidente da República a opinião da Nação, que ele colhe junto aos parlamentares, que ele representa, junto ao Congresso Nacional, que ele representa e que é caixa de ressonância da Nação.

Assim ele faz esse duplo papel de ser o coordenador administrativo e o coordenador político. Além do mais, deve interferir na nomeação dos Ministros de Estado, ele deve ser ouvido quanto à exoneração dos Ministros de Estado. Ele, portanto, leva a opinião da Câmara sobre as tendências que lá predominam, no sentido de se ter escolhido este ou aquele. Mas - Presidente da República é o chefe de Estado, chefe de governo. Ele tem, administração pública nas suas mãos. Ele só tem no Primeiro-Ministro um auxiliar, que não é um mero auxiliar, é o auxiliar principal do Presidente da República, que é encarregado do respaldo político.

Eu não quero me delongar, senhor ministro, porque eu sei que esse debate ainda deve se prolongar com a participação de nosso ilustre professor Celso Lafer e daqueles que aqui estão, mas eu queria deixar apenas esta idéia da necessidade imprescindivel de passarmos da realidade para a construção de um modelo. De não querermos a construção de um modelo teórico, que não seja aplicável à realidade, um modelo que busque eficácia, porque o modelo que gera impasse não vai, sem dúvida nenhuma, alcançar os objetivos desta Constituinte, que é uma grande reforma institucional que viabilize a mudança e garanta a estabilidade tão necessária à vida brasileira. 